\title{
ESTALLIDO SOCIAL EN CHILE Y PROCESOS DE PATRIMONIALIZACIÓN: UN PARADIGMA DE RESIGNIFICACIÓN DE LAS MEMORIAS
}

Explosão social no Chile e processos patrimoniais: um paradigma para a resignificação das memórias

Social uprising in Chile and patrimonialization processes: a resignification paradigm of memories

Mario Ferrada Aguilar

Instituto de Historia y Patrimonio, Facultad de Arquitectura y Urbanismo de la Universidad de Chile. Santiago, Chile.

mferrada@uchilefau.cl

https://orcid.org/0000-0001-6995-0926



Comunicación derivada de la línea de investigación "Claves de nuevos procesos de patrimonialización en la ciudad histórica y la arquitectura de Chile", desarrollada desde 2020 al interior del Instituto de Historia y Patrimonio de la Facultad de Arquitectura y Urbanismo, Universidad de Chile. 


\section{RESUMEN}

En los últimos años, a nivel mundial y local, asistimos a un cambio profundo del paradigma respecto de lo que tradicionalmente hemos asumido como manifestación del patrimonio. En parte, esta transformación conceptual y metodológica se debe a la emergencia de los procesos de patrimonialización, motivados por conflictos sociales que operan en contra de los discursos institucionalizados del patrimonio. De ello resultan resignificaciones de las historias y las memorias en el territorio, la ciudad y la arquitectura, asociadas a nuevas categorías de patrimonio que es necesario atender. El presente trabajo aborda este nuevo paradigma, tomando como caso el denominado "estallido social", que afecta a Chile desde el 18 de octubre de 2019 y que se extiende hasta la actualidad. Más allá de percibirse como un fenómeno destructivo, que inicialmente apunta a aspectos de carácter sociopolítico, la presencia del conflicto en la sociedad nacional señala una aguda crítica al sistema de representación del patrimonio. En su trayectoria espacio-temporal surgen nuevas prácticas socio-espaciales que satisfacen las expectativas de memoria de las comunidades respecto de una realidad en transformación. El artículo pretende aportar al ámbito de la arquitectura y el ambiente construido, en cuanto permite reflexionar sobre la transformación de los significados y valores de los patrimonios que emergen en la realidad cotidiana de nuestras ciudades. Mediante una metodología descriptiva, basada en documentos de prensa recientes, se abordan algunas situaciones emblemáticas del problema, manifestadas en las áreas urbanas consolidadas de La Serena, Valparaíso, Santiago, Concepción, Temuco y Punta Arenas. En ellas, las operaciones de patrimonialización visibilizan los contrastes entre los discursos del Estado y los producidos por organizaciones sociales, la resignificación de elementos del patrimonio tradicional y la emergencia de la ciudad como espacio de negociación de las memorias. De lo anterior, se infiere la renovación de los valores y atributos tradicionalmente asignados a los monumentos, ya sea en su condición objetual, arquitectónica o urbana, así como también se detecta la potencialidad del patrimonio, como canalizador de diálogo, convivencia y cohesión en el continuo debate por las historias y las memorias en conflicto.

Palabras Clave: conflicto social, procesos de patrimonialización, discursos, memorias, estallido social en Chile

\section{RESUMO}

Nos últimos anos, global e localmente, assistimos a uma mudança profunda no paradigma relativo àquilo que tradicionalmente assumimos como uma manifestação do patrimônio. Em parte, esta transformação conceptual e metodológica deve-se à emergência de processos de patrimonialização, motivados por conflitos sociais que operam contra os discursos institucionalizados do patrimônio. Isto resulta em ressignificações das histórias e memórias no território, na cidade e na arquitetura, associadas a novas categorias do patrimônio que precisam de ser abordadas. Este trabalho aborda esse novo paradigma, tomando como caso de estudo a chamada "explosão social" (estallido social, em espanhol), que tem afetado o Chile desde 18 de outubro de 2019 e que continua até o os dias de hoje. Muito além de uma visão dessa "explosão" como um fenômeno destrutivo, que aponta inicialmente a aspectos de natureza sociopolítica, a presença do conflito na sociedade nacional é um indicador de uma forte crítica ao sistema de representação do patrimônio. Em sua trajetória espaço-temporal, surgem novas práticas sócio-espaciais que satisfazem as expectativas de memória das comunidades com respeito a uma realidade em transformação. $O$ artigo pretende contribuir para o campo da arquitetura e do ambiente construído, na medida em que nos permite refletir sobre a transformação dos significados e valores dos patrimônios que emergem na realidade quotidiana das nossas cidades. Por meio de uma metodologia descritiva, baseada em documentos de imprensa recentes, são abordadas algumas situações emblemáticas do problema, manifestadas nas zonas urbanas consolidadas de La Serena, Valparaíso, Santiago, Concepción, Temuco e Punta Arenas. Nelas, as operações de patrimonialização tornam visíveis os contrastes entre os discursos do Estado e os produzidos pelas organizações sociais, a ressignificação de elementos do patrimônio tradicional e a emergência da cidade como espaço de negociação de memórias. De tudo isto, infere-se a renovação dos valores e atributos tradicionalmente atribuídos aos monumentos, seja na sua condição objetal, arquitetônica ou urbana, bem como a potencialidade do patrimônio como canal de diálogo, convívio e coesão no debate contínuo das histórias e memórias em conflito.

Palavras-Chave: conflito social, processos de patrimonialização, discursos, memórias, explosão social no Chile

\section{ABSTRACT}

In recent years, both globally and locally, a profound change in the paradigm has been seen with respect to what has been traditionally accepted as a manifestation of heritage. In part, this conceptual and methodological transformation is due to the emergence of patrimonialization processes, driven by social conflicts that go against the institutionalized discourses of heritage. This results in resignifications of the stories and memories in the territory, the city and the architecture, associated with new categories of heritage that need to be addressed. This work is about this new paradigm, taking as a case the so-called 'social uprising, which has affected Chile since October 18 ${ }^{\text {th }}, 2019$. Beyond being perceived as a destructive phenomenon, which initially targets aspects of a socio-political nature, the presence of the conflict in Chilean society points to a sharp criticism of the heritage representation system. In its spatio-temporal trajectory, new socio-spatial practices arise that satisfy the memory expectations of the communities regarding a transforming reality. The article aims to contribute to the field of architecture and the built environment, insofar as it allows reflecting on the transformation of meanings and values of heritage that emerges in the daily reality of our cities. Using a descriptive methodology, based on recent media documents, some emblematic situations of the problem are addressed, manifested in the consolidated urban areas of La Serena, Valparaíso, Santiago, Concepción, Temuco, and Punta Arenas. In them, the patrimonialization operations make visible the contrasts between the discourses of the State and those produced by social organizations, the resignification of elements of traditional heritage and the emergence of the city as a space for negotiation of memories. From all this, the renewal of the values and attributes, traditionally assigned to monuments, is inferred, whether in their objectual, architectural or urban condition, as well as the potentiality of heritage, as a channel for dialogue, coexistence, and cohesion in the ongoing debate about conflicting stories and memories.

Keywords: social conflict, patrimonialization processes, discourses, memories, social uprising in Chile 


\section{INTRODUCCIÓN}

\section{DEL CONFLICTO SOCIAL A LOS PROCESOS DE PATRIMONIALIZACIÓN}

El conflicto social que se instala en Chile a partir de 2019 responde a una forma de socialización, destinada a la búsqueda de una relativa cohesión social, a través de "acciones recíprocas" entre diferentes individuos y grupos que bregan por coexistir espacial y temporalmente (Simmel, 20 I4, p. 103). La experiencia subjetiva que conlleva el conflicto social induce una determinada forma de percibir los problemas de la realidad. Se descubre que los conflictos no solo cuestionan o alteran los órdenes de corto plazo, sino, sobre todo, modifican en el largo plazo las mentalidades colectivas, gestándose miradas epistémicas, giros intelectuales y comportamientos sociales irreconocibles antes del movimiento social (Lorenzo Cadarzo, 200 I, p. 250).

Detrás de los conflictos sociales se elaboran potentes procesos de patrimonialización, en los que se detectan diversos puntos de vista e intereses en juego a cargo de grupos sociales heterogéneos, que tienen como resultado una crítica a los discursos "autorizados" que se ejercen en el momento de despliegue de la crisis social. Sin embargo, como señala García Canclini, las crecientes desigualdades en los procesos de formación y apropiación del patrimonio cultural, exige estudiarlo "como un espacio de lucha material entre las clases, las etnias y los grupos de las sociedades contemporáneas" (1999, p. 18). Siguiendo a Ballart, el valor en el patrimonio es un concepto relativo, no inherente a las cosas que designa, y depende de la percepción y el comportamiento humano dotado de referencias históricas, intelectuales, culturales y psicológicas (1996, p. 218). En dichos procesos, los elementos culturales y naturales son seleccionados y reelaborados en respuesta a nuevos usos sociales (Roigé y Frigolé, 2010, p. 12) y las normas o cánones tradicionales heredados son cuestionados, impugnados y subvertidos, precisamente a partir del momento en que se alza una nueva categorización de comprensión del presente (Davallon, 2006, p. 95).

De acuerdo a Iniesta (2009, p. 479), este proceso comprende cuatro fases: a) identificación, mediante pruebas, de los elementos que un colectivo social considera significativas; b) su validación por parte de una institución legitimada socialmente; c) su proclamación y marcaje para hacer visibles los valores de esos elementos; y d) la transmisión y activación para la preservación de la integridad del patrimonio resultante, de manera de mantenerlo en los circuitos de la producción del conocimiento, de los imaginarios y de las memorias. Esto implica que la sociedad civil, inmersa en el conflicto, no solo participa de algunas fases de la cadena valorativa del patrimonio, sino en la integralidad del proceso (Sánchez Carretero, 2017, p. 196197). A la larga, lo que se reivindica en la relación conflicto social y formación del patrimonio, es el derecho a una memoria social que se pretende colectiva. La activación del patrimonio que así surge es, como indica Prats (2005, p. 18-19), el resultado de una actividad fundamentalmente política, donde los individuos y los colectivos aparecen como un lugar de materialización de prácticas sociales y ellos 


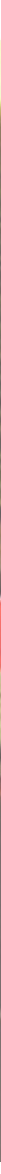

Figura 1

Manifestación de

agrupaciones sociales

"El patrimonio somo

todos", Santiago de

Chile, 2014. Fuente:

Radio Cooperativa ( 24

mayo 2014) (https://

www.cooperativa.cl/

noticias/cultura/

patrimonio-cultural/

cerca-de-4-mil-

personas-marcharon-

personas-marcharon-

por-el-patrimonio-

go/2014-05-24/195400.

html). mismos son productores y reflejos de sus mismas representaciones (Larraín, 2010, p. 49).

La resignificación de los valores del patrimonio, corresponde a un proceso espacio-temporal que surge en paralelo con una crisis de su condición de representatividad, en el complejo marco de las relaciones conflictivas que protagonizan los distintos actores sociales [Figura I]. Todo ello explica por qué los objetos del patrimonio, sean espacios públicos, arquitecturas u objetos de rememoración, puedan ser en determinado momento histórico sujetos de veneración de grupos de poder, para transformarse en otro momento en sujetos de crítica y reelaboración de significados. Por otro lado, en este fenómeno concurre la tensión monumento y documento, en la que el primero no tendría existencia histórica sin su transformación en un testimonio documental de época o, dicho de otra forma, en un portador y anclaje de discursos sobre una interpretación interesada del pasado. La conversión de un monumento en documento trae aparejada la necesidad testimonial de una lectura de la historia y de una forma de discurso nacida en el seno de un grupo que controla el poder y los saberes asociados. 


\section{METODOLOGÍA}

\section{ANÁLISIS REPRESENTACIONAL DEL PATRIMONIO A TRAVÉS DE SUS DISCURSOS, HISTORIAS Y MEMORIAS}

Según aseveraba Riegel en 1903, el papel monumental del patrimonio afirma su capacidad de representación de significados y valores en el presente, mediante una conciencia ciudadana que intenta recoger un sentido de contemporaneidad desde sus historias pasadas, para, de alguna forma ser impulsada a una idea -o proyecto- de futuro (1987, p. 23). En esta medida, la estructura misma del espacio, sus arquitecturas y monumentos se comportan como el espejo que refleja esas ausencias históricas, pero también voces y recuerdos que se actualizan al fragor de las demandas sociales.

La crisis de representación del patrimonio y sus monumentos-documentos, es algo que afecta a la imagen de la materia o la materia de la imagen. En este proceso histórico, emerge la dinámica de la obsolescencia de significados y valores de los elementos considerados patrimoniales, que es fruto del debilitamiento de los discursos que han sido fuertes en una época, por la hegemonía ejercida por unos grupos de poder sobre otros. Una crisis de representación patrimonial, se manifiesta entonces, cuando se experimenta la 'ausencia de la presencia', es decir, cuando se producen nuevos sentidos en respuesta a la historicidad de los cambios socio-culturales que operan en una comunidad. En un incesante movimiento de presencias y ausencias, la realidad representada del patrimonio no refleja exactamente ni de modo estático la primera naturaleza del existir cotidiano y natural del ser humano (Lefebvre, 2006, p. 30).

Por la complejidad de los temas que surgen en el proceso de patrimonialización que deriva del conflicto social chileno, se ha utilizado un enfoque que entiende al patrimonio como un sistema de representaciones sociales, que se compone de dos naturalezas dialógicas. La primera de ellas está determinada por su presencia físico-material, a través de las diversas categorías de patrimonio dignas de conservación y regulación: territorios, constructos urbanos, arquitectónicos, objetos, etc. En cambio, la segunda naturaleza, es de tipo representacional, la imagen que nos hacemos de la primera y que es adquirida y transmitida socialmente mediante el acto del lenguaje, producida intelectualmente, cuyos ingredientes son las memorias, los recuerdos y los imaginarios (Lefebvre, 2006, p. 30).

Con objeto de caracterizar el proceso de patrimonialización que se desarrolla actualmente como efecto del estallido social en Chile, a título ilustrativo, se han tomado casos relevantes ocurridos en algunas áreas urbanas del país, tales como La Serena, Valparaíso, Santiago, Concepción, Temuco y Punta Arenas. Se les seleccionó por su calidad de monumentos y/o espacios públicos presentes en la memoria nacional y/o local, en los cuales se han manifestado permanentes cuestionamientos relativos a los significados a ellos atribuidos, mediante ingentes alteraciones físicas y espaciales. No se pretende aquí evaluar la integralidad del patrimonio nacional, ni desarrollar un análisis exhaustivo de las situaciones señaladas, sino establecer la presencia del 


\section{ANÁLISIS \\ ESTALLIDO SOCIAL EN CHILE ACTIVADOR DE UN NUEVO PARADIGMA DE VALORACIÓN DEL PATRIMONIO CULTURAL}

\footnotetext{
1 La cronología del alzamiento popular marca los siguientes hitos: el 4 de octubre de 2019, el Gobierno anuncia un alza de 30 pesos en el pasaje del metro urbano. El 14 del mismo mes estudiantes secundarios y universitarios se organizan y llaman a "evadir masivamente" el pago del transporte colectivo. El día 18 el movimiento se radicaliza y, en tan solo una semana, las protestas escalan en magnitud con la destrucción de numerosas estaciones y líneas de metro.
}

fenómeno en aquellos ejemplos que han sido materia de la opinión pública, intentando exponer sus similitudes y diferencias.

El material documental utilizado consiste en referencias bibliográficas especializadas y documentos recientes, compuestos por iconografías, fotografías y artículos de prensa. A través de su indagación es posible detectar las voces en conflicto, los imaginarios sociales y los nuevos tipos de patrimonio que estarían surgiendo en el proceso. La patrimonialización señalada, se encara a través de tres perspectivas: a) la elaboración de discursos enfrentados, entre el Estado y los colectivos sociales; b) la resignificación de los espacios y objetos de memoria patrimonial, dados por monumentos, espacios urbanos y arquitecturas connotadas; y c) la activación de las prácticas en la ciudad, como espacio de negociación de memorias.

\section{a] De los nuevos discursos a la activación de las memo- rias contradictorias del patrimonio.}

El 18 de octubre de 2019 se desencadena en Chile el denominado "estallido social" 1, evento de denuncia y protesta transversal que no se veía desde los tiempos de la dictadura cívico militar (1973-1989). El fenómeno, no exento de violencia, ha puesto en evidencia una fractura en la sociedad chilena, que trasciende las posiciones ideológicas o partidistas. Junto con la exigencia de condiciones de vida digna y equitativa, se ha cuestionado el nivel de representación de las instituciones y de los elementos autorizados del patrimonio cultural nacional. A partir de este momento se desata una verdadera revolución en los espacios públicos y en los monumentos en las principales ciudades del país. Las convocatorias a base de redes sociales, marchas y ocupación urbana se convierten en un ritual constante [Figura 2].

En ciudades como La Serena, Valparaíso, Santiago, Concepción, Temuco y Punta Arenas, la derivada patrimonial ha sido la inédita aparición de prácticas espaciales y de uso, con intentos de resignificación de los símbolos de la memoria histórica nacional. El enfrentamiento se ha desatado esencialmente en el plano discursivo, entre las instituciones tradicionales de la República y del Estado, versus las organizaciones sociales inmersas en el conflicto. Un importante porcentaje de la crítica social apunta al discurso autorizado del patrimonio, sistematizado por el Estado, las élites y las comunidades académicas. Esto ha llevado a que el patrimonio protegido por la legislación, funcione como dispositivo táctico del rechazo, no por sus cualidades intrínsecas, sino por los discursos de hegemonía cultural que encarnan. Para dar visibilidad a los discursos marginados por el sistema tradicional se han intervenido espacios públicos, lugares de memoria, arquitectura tradicional y monumentos públicos.

Bajo esta lógica de enfrentamientos, es posible identificar dos dimensiones del discurso, en los que se revelan modos distintos de percibir y evaluar la realidad:

El primero de ellos corresponde a los discursos institucionalmente autorizados, emanados desde las estructuras del poder, representados por los organismos del Estado, en particular por el Ministerio de las 


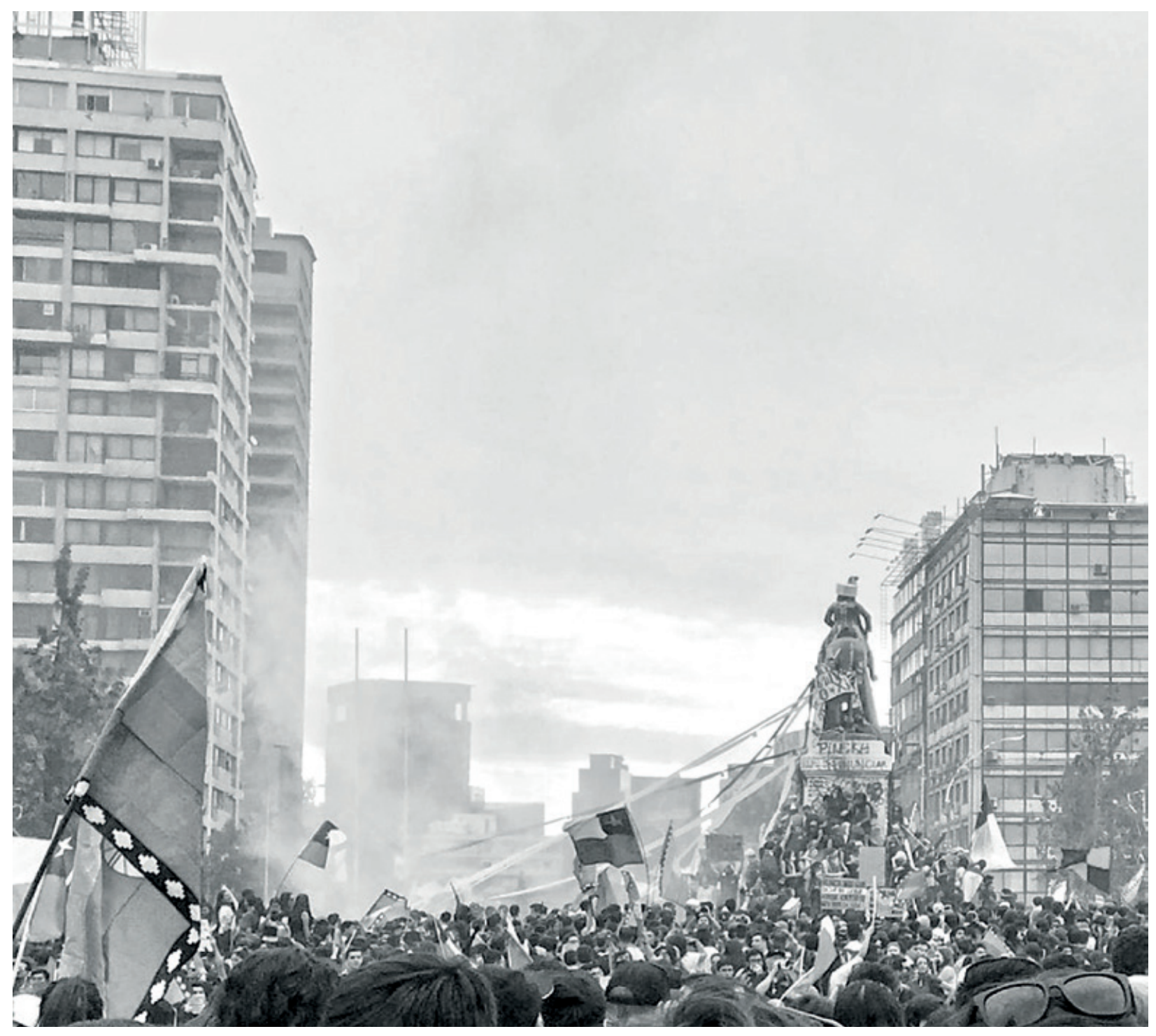

Figura 2

Las persistentes manifestaciones del estallido social de Chile desarrolladas Chile desarrolladas del centro histórico del centro histórico
de Santiago, lugar de Santiago, lugar
rebautizado por los grupos demandantes como "Plaza de la

Dignidad".

Fuente: Fotografía

inédita de Fernando

Dowling Leal (2020).
Culturas, las Artes y el Patrimonio, así como por grupos de decisión política y económica y, también de comunidades académicas y disciplinares. En un segundo grupo, tenemos el flujo de los discursos socialmente radicalizados, de conformación más o menos espontánea, representados por comunidades, grupos sociales, etnias, entidades gremiales y políticas que se declaran fuera del sistema tradicional de decisiones.

En el discurso institucionalmente autorizado, el estallido social se percibe como una amenaza al patrimonio histórico y cultural que la Nación ha logrado instituir, a través de la Ley de Monumentos Nacionales y la Ley General de Urbanismo y Construcciones. En este caso, la memoria, supuestamente compartida, tiende a cerrarse en sí 
misma, a tornarse estática y monolítica, a convertirse finalmente en un poderoso mecanismo de negación y de exclusión. En este caso, el discurso patrimonial se reviste de un carácter mítico y se erige como una especie de fortaleza autodefensiva. En cambio, en el discurso socialmente radicalizado, es posible observar una tendencia a horizontalizar el problema y a subvertir el canon de las instituciones formales. Los discursos de la élite resultan extraños e ininteligibles para la realidad vivenciada de los grupos sociales demandantes. Un discurso que impugna y que, al mismo tiempo, expone la erosión de la figura del Estado, de los organismos empresariales y de las estructuras jurídico-legales. Los discursos sociales reflejan una verdadera crisis de representación con un explícito cuestionamiento a los significados y valores de un conjunto de patrimonios que por largos años fueron incuestionados [Figuras 3 y 4 ].

En la realidad del conflicto, se determina un flujo representativo de lo que se entiende por patrimonio, mediante el cual se redefinen las relaciones entre los modos de existir de la sociedad, sus historias y sus memorias. Se comprueba que cada representación de las identidades anuladas y/o marginadas del discurso institucionalizado, remite a otras, en una sucesión temporal, hasta construir una red compleja de significados que aún no logran estabilizarse (Castoriadis, 2013, p. 505). Es, por ejemplo, lo que explícitamente aparece en el campo de las memorias reclamadas por los pueblos originarios, en especial el mapuche, que tiende a visibilizarse y superponerse a las memorias heridas del pueblo criollo, exigiendo dignidad en un espacio ciudadano que históricamente se le ha negado cultural y políticamente.

Ambos tipos de discursos se territorializan en la ciudad, en los espacios de civilidad y en los aparatos arquitectónicos, cambiándoles el sentido estático y reverencial que hasta este momento habían mostrado. El flujo discursivo se inserta en un marco actual de modificaciones legales relevantes, a través de los cuales se tensiona el relato de la historia que ha dado lugar a la presencia de los monumentos y del espacio signado por unos pocos para la memoria de la Nación. Nos referimos a los proyectos de ley de Patrimonio Cultural, de Integración Social y Urbana, la modernización del Sistema de Evaluación de Impacto Ambiental (SEIA), las indicaciones a los proyectos de ley que crean el Ministerio de Pueblos Indígenas y el Consejo Nacional y los Consejos de Pueblos Indígenas. Para los detractores, estas iniciativas legales incidentes en la cultura y el patrimonio, solo esconderían la finalidad de consolidar la presencia del mercado como eje de la toma de decisiones, generando aún mayor fragilidad a la actual. Particularmente, el proyecto de Ley de Patrimonio Cultural, que sustituiría a la actual Ley de Monumentos Nacionales -que data de 1970-, se ha convertido en el telón de fondo para la crítica de algunas organizaciones sociales situadas al margen del discurso autorizado. A este respecto, en marzo 2020, la "Comunidad por el Patrimonio de Chile" declaró que el Gobierno estaba actuando 


\section{b] Resignificación de los espacios ciudadanos y los obje- tos de memoria patrimonial}

En el conflicto social los espacios urbanos han sido brutalmente afectados por la destrucción física, pero también han sido relevados en su rol de lugares de reconstrucción de las memorias, entrando en conflicto con la historia autorizada de la ciudad. En dichos lugares, las manifestaciones sociales, los imaginarios y las identidades se expanden a plazas y calles tradicionales que forman la ramificación del espacio público resignificado. La moderna resignificación de los monumentos que vivimos en Chile se está manifestando como respuesta al contexto sociopolítico de un tiempo social claramente definido. A diferencia del papel conmemorativo de los monumentos intencionados, que eran promovidos por las élites ilustradas, en el caso que analizamos ellos están siendo el resultado de una apropiación subjetiva, mediante la que el observador-sujeto social queda establecido como el factor central en el proceso de constitución de valores cada vez más relativos a puntos de vista en permanente cambio (Riegl, 1987, p. 25).

En Santiago, el circuito compuesto por la Plaza Italia, parte de la Alameda Bernardo O'Higgins, Parque Forestal y Avenida Vicuña Mackenna, se ha consolidado como nodo de red para nuevos significados y valores atribuidos a un patrimonio en estado de elaboración. La actual Plaza Italia fue rebautizada como Plaza de la Dignidad, lo que refleja el rechazo a la injusticia y falta de representatividad de los valores más transversales de la sociedad chilena. A diferencia de acciones masivas tradicionales ejercidas en la Plaza Italia, aquí el emblema patrio de la Nación convive con banderas mapuche y otros símbolos sacados de la cotidianeidad social, dando cuenta de la existencia real de una diversidad étnica, social e ideológica, que no ha sido reconocida en la multiculturalidad de la identidad nacional. Por 98 años en el centro de esta plaza lució la estatua del General Manuel Baquedano, obra del arquitecto Gustavo García del Postigo y el escultorVirgilio Arias Cruz, levantada por erogación popular e inaugurada en 1928 en conmemoración de las batallas de la Guerra del Pacífico. Con fecha 10 de marzo 2021, el Consejo de Monumentos Nacionales decretó el retiro del monumento del lugar y la construcción de un cierre perimetral metálico, con la finalidad de ejecutar trabajos de conservación preventiva y restauración, además de obras de resguardo del pedestal de piedra y de los restos del "soldado desconocido" que allí descansan.

El monumento al General Baquedano resume las tensiones experimentadas en la Plaza Italia, como si este lugar atesorara una profunda densidad de significados históricos que requieren de una reinterpretación en el Chile contemporáneo. La figura de Baquedano "sigue vigente, y vuelve a tomar vida, no es un monumento muerto, es un monumento vivo" (De Ramón, 15 enero 2020). En la actualidad y a pesar de la pandemia mundial por Covid-19, la Plaza Italia ha persistido como lugar de enfrentamientos, y la estatua de Baquedano cada 

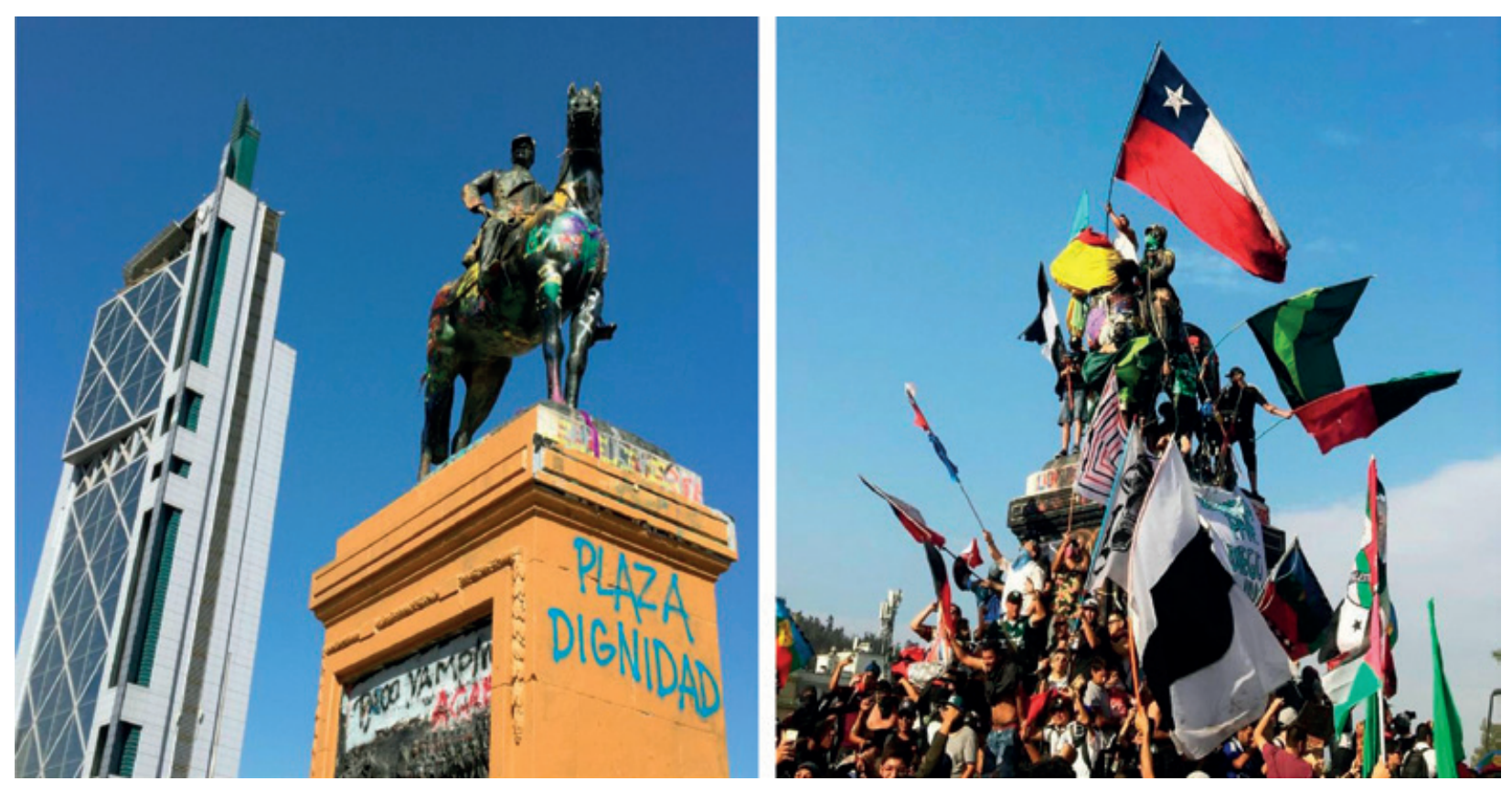

Figura 5

Plaza Italia, lugar de reapropiaciones y transformaciones sociales de los

símbolos del

patrimonio histórico

y cultural de la

Nación. Al centro

vación. Al centro

urbano, la imagen

del General

Manuel Baquedano,

convertida en botín

de guerra dentro de

flujos discursivos

y de memorias aún

no estabilizadas.

Fuente: Fotografía

inédita de Fernando

Dowling Leal (2020). vez más agredida ha experimentado el intento de sacarla a fuerza de cortar las patas del caballo del militar [Figura 5].

En Valparaíso, un caso singular lo representa el entorno al Congreso Nacional. Aquí, los reclamos a los símbolos del poder político son evidentes, pues ocupan gran parte de la avenida Argentina, avenida Pedro Montt, calle Victoria y plaza O'higgins. En este espacio urbano se lee una reacción visceral contra las élites y la memoria normalizada de su poder. En la ciudad también se registra el rebautizo el 3 de diciembre 2019 de la Plaza Aníbal Pinto como Plaza de la Resistencia, que subraya la función de trinchera que este espacio histórico ha desarrollado en las protestas. En ambos casos se observa un rechazo generalizado a una historia y memoria oficial encarnada en el espacio urbano. Cabe señalar que en esta ciudad el fenómeno se muestra doblemente crudo, como consecuencia de la endémica condición de pobreza, abandono y deterioro que experimenta el espacio público y la arquitectura, en general, y la del patrimonio, en particular. Este hecho fomenta que las acciones de patrimonialización o de trasgresión de los monumentos protegidos legalmente cuenten con un escenario urbano y ambiental proclive para la efervescente denuncia social [Figura 6].

Al sur de Chile, la ciudad de Concepción ha visto alterado sus ritmos, rituales e imágenes de la cotidianeidad. El radio de acción espacial ha abarcado el Arco de Medicina de la Universidad de Concepción, el barrio cívico, la Plaza Independencia, el sector de los Tribunales, y la red de la avenida Bernardo O'Higgins y Paicaví [Figura 7]. En 



Figura 6

Valparaíso.

Ocupación de la

Avenida España y

entorno del Congreso

Nacional, en la

"marcha de todas las marchas" convocada en Valparaíso el 28 de octubre de 2019. Fuente: Aranda (2020, p. 58).
Figura 7

Concepción.

Concentración en la Plaza de Tribunales de Concepción, 23 de de Concepción, 23 Fuente: Televisión Universidad de Concepción (23 octubre 2019) octubre 2019) (https://www.tvu cl/prensa/tele10/05/a-un-ano-delestallido-socialcuales-son-lasdemandas-ciudadanaspendientes.html) 
Figura 8

Los monumentos

públicos actúan

como dispositivos

de resignificación

de historias

yuestran las figuras

muestran las figu

de poeta Rubén

escultóricas de la

Fuente Alemana,

ubicadas en el

radio histórico de

Santiago.

Fuente: Fotografías

de Francisco Ubilla

(2020) (https : //

elpais.com/

cultura/2020/01/23/

actualidad/

$1579806166 \quad 111949$.

html)
Concepción, el estallido social ha presentificado lugares efímeros que denotan capas superpuestas de significados sociales, que traducen un "gran proyecto temporal que simboliza las luchas por los derechos y por las libertades" (De Souza 2020, p. 160)

Por su parte, los objetos de memoria pública resignificados han sido mayoritariamente estatuas, bustos y fuentes que retratan hechos, personajes y símbolos históricos relevados como reverencias de memoria por las élites de fines del siglo XIX y primeras décadas del XX. Según un catastro efectuado por el Consejo de Monumentos Nacionales, entre octubre 2019 y febrero 2020, los monumentos nacionales dañados en todo el país ascienden a 1.353. Los principales focos de agresión lo constituyen representaciones de hechos, héroes y personajes históricos de la conquista hispana de los siglos XVI y XVII, y los signos republicanos de los siglos $X I X$ y $X X$. En los monumentos intervenidos se evidencian lecturas que confrontan el orgullo nacional con las historias olvidadas (Gaete, 30 junio 2020), expresando un disgusto por los símbolos eurocentristas, no coincidentes con las representaciones de los pueblos originarios (mapuche, por sobre todos).

En Santiago, obras escultóricas de gran valor histórico y artístico, la mayoría provenientes del Centenario de la Independencia Nacional (1910) han sucumbido al grafiti y al zamarreo de las turbas enardecidas Entre muchos otros casos, tenemos el monumento a Rubén Darío, inaugurador del modernismo literario en Latinoamérica [Figura 8] y
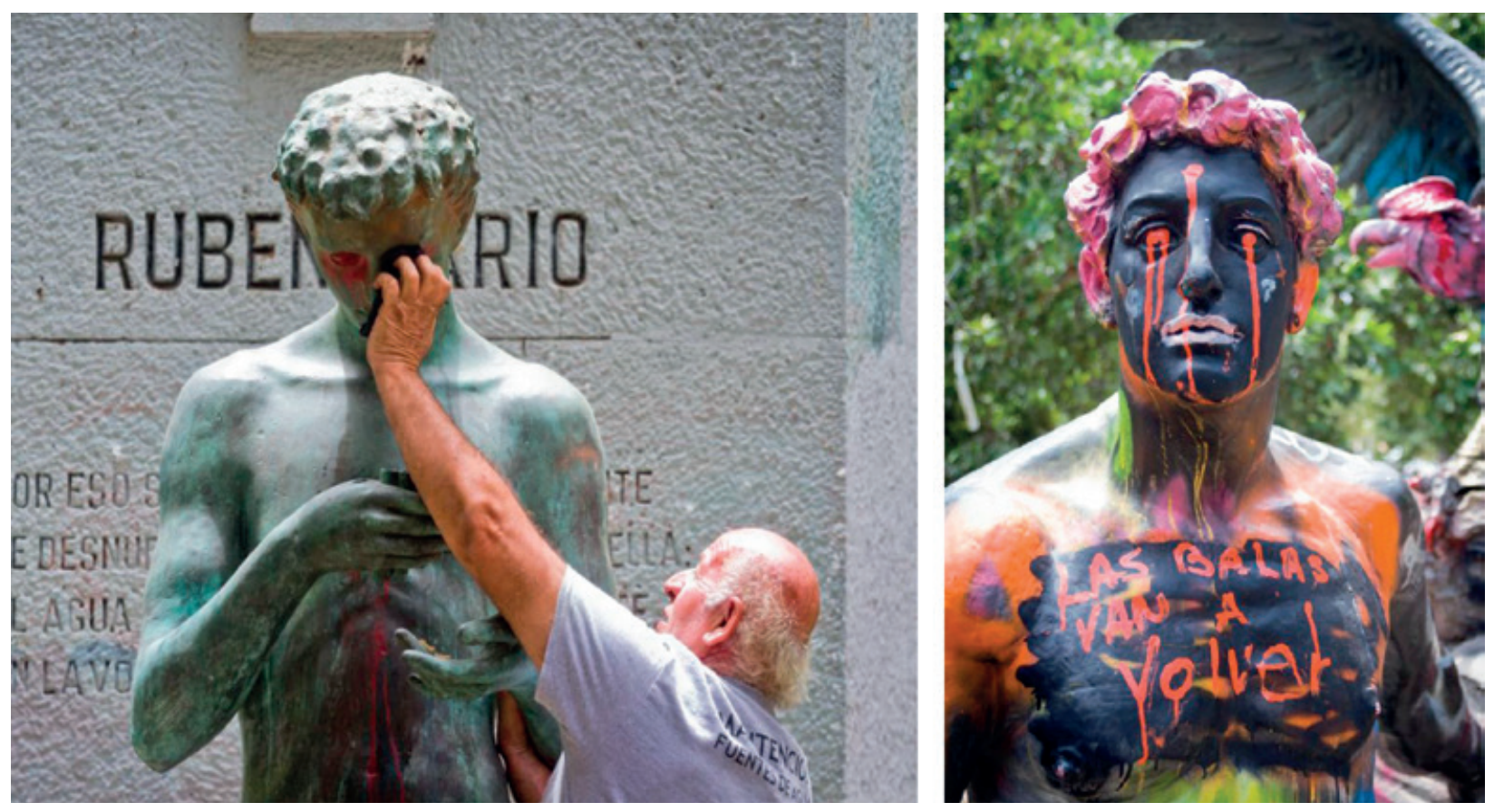
Figura 9

Plaza Sotomayor.

Monumento a los

Héroes del Combate

Naval de Iquique,

emplazado al centro

cívico ceremonial

de la plaza

Rafael Sotomayor,

sector Puerto

de Valparaíso.
Producto de los

constantes ataques

al monumento, la

Armada de Chile

refuerza la

seguridad del lugar

donde reposan los

restos de Arturo

Prat y otros

héroes navales.

Fuente: Sebastián

Fisternas, Aton

chile, 2020. la Fuente Alemana del Parque Forestal. En la Alameda Bernardo $O$ 'higgins, los muros exteriores del Centro Cultural Gabriela Mistral (ex UNCTAD) han recibido intervenciones populares que, en su momento el Gobierno intentó borrar, encontrándose con la férrea oposición de sus autores. En esta operación de resignificación no hubo realmente destrucción, sino una especie de superposición de complejos significados históricos.

En Valparaíso, el Monumento a los Héroes de lquique, levantado en I 883 en conmemoración del Combate Naval, emplazado al centro de la Plaza Sotomayor ha sufrido constantes rayados [Figura 9]. La Armada de Chile, institución que resguarda este patrimonio nacional, junto con condenar este "cobarde ataque", declaró que "el daño afecta la memoria e historia de todos quienes hemos nacido en esta patria (...). No permitiremos que un acto como este se vuelva a repetir y utilizaremos todos los recursos que nos otorga la ley para proteger el lugar donde descansan nuestros héroes patrios" (CNN, 23 febrero 2020).

En la ciudad de La Serena, la estatua recordatoria del militar español Francisco de Aguirre, ubicada en la Avenida Panamericana (Paseo de las Esculturas) y ejecutada en Madrid en el año 1950 por el escultor Juan Adsuara, en el marco del Plan Serena, durante el Presidente Gabriel González Videla (1946-1952), fue derribada y quemada, a causa de lo cual sufrió deformaciones en el rostro. En el mismo lugar, el monumento fue sustituido por otro, en honor a Mi-

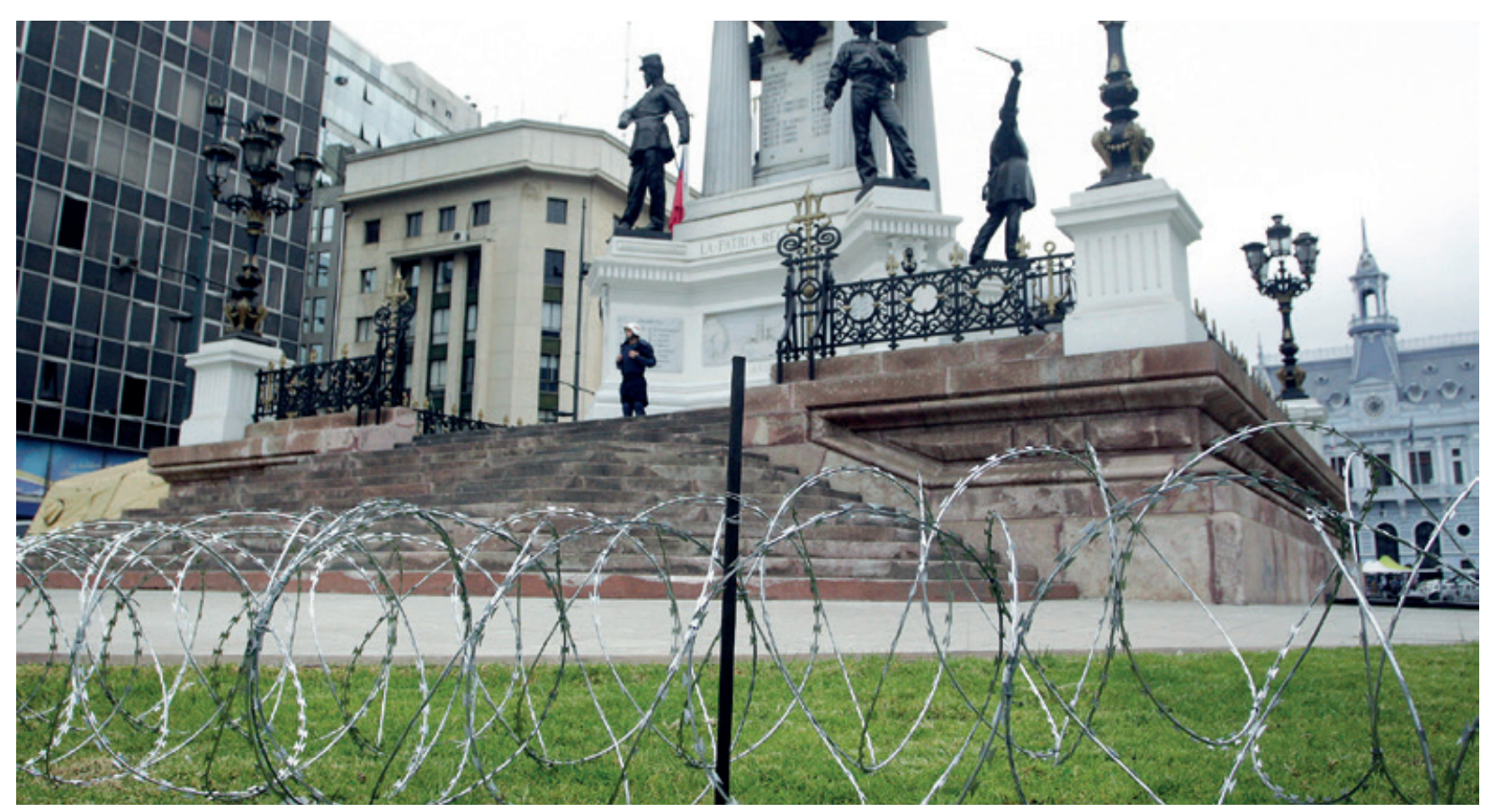




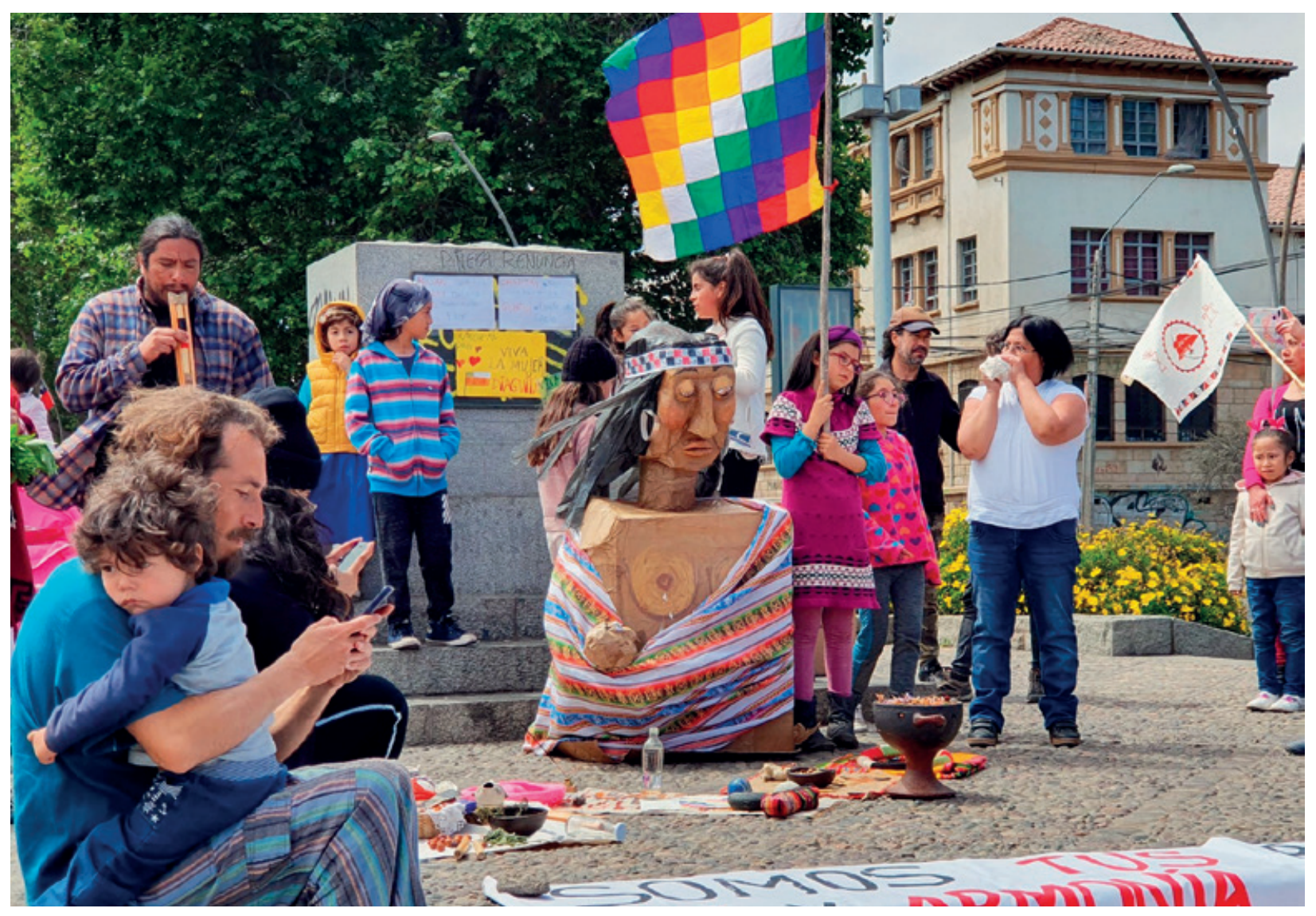

Figura 10

En la ciudad de

La Serena, el

monumento a la

figura de Francisco

de Aguirre,

sustituido por la

figura de diaguita

de Milanka.

Fuente:

Fotógrafo Lautaro

Carmona (2019)

Carmona (2019)

(https://Www.

cl/2019/10/24/en-

la-serena-instalan-

torso-de-mujer-

diaguita-donde-

se-encontraba-

la-estatua-de-

francisco-de-

aguirre/) lanka o mujer diaguita, elaborada con papel, cartón y pintura [Figura 10]. La instancia de su entronización como nuevo monumento se celebró con una ceremonia diaguita, y la colectividad autora demandó el cambio de nombre de la Avenida Francisco de Aguirre por Avenida Diaguitas. Tiempo más tarde, en la refriega social, Milanka también sucumbió al fuego por parte de desconocidos. Este hecho grafica la obsolescencia que ha experimentado el monumento a Francisco de Aguirre, por largos años parte del imaginario colectivo de la ciudad, así como otras figuras similares existentes en el país, ante el acrecentamiento en los últimos años de los discursos que reivindican los contenidos indigenistas. Demuestra, además, que en un clima social de conflicto la representatividad de los elementos nuevos es efímera y cambiante.

En Temuco, la estatua Pedro de Valdivia, conquistador español y fundador de la ciudad de Santiago, fue decapitada. Por su parte, en la mano de la escultura del toki mapuche Caupolicán, símbolo de la resistencia contra la conquista española, cuelga la cabeza del aviador 

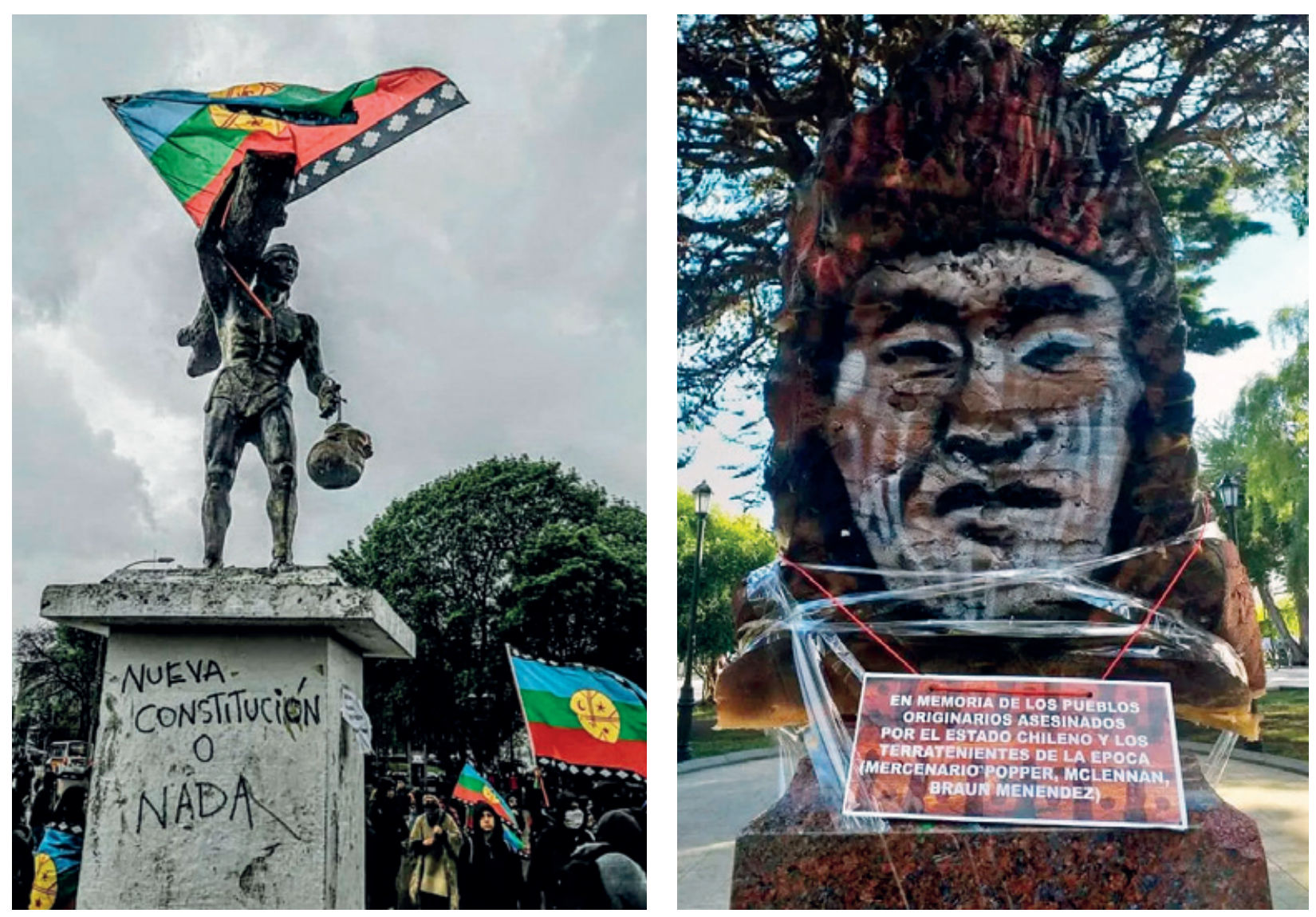

\section{Figura 11}

Al sur de Chile, en la ciudad de Temuco la figura del toki mapuche Caupolicán sosteniendo la cabeza de la estatua del aviador chileno Dagoberto Godoy, sacada de su lugar original. Engalana la escena, la bandera del pueblo mapuche. Fuente: El desconcierto El desconcierto 2019) (https: / / www. eldesconcierto.cl/ nacional/2019/11/29/ temuco-mas-justiciamenos-monumentos. html)
Figura 12

En el extremo sur de Chile, en la Plaza de Armas de la ciudad de Punta Arenas, el busto del estanciero José Menéndez fue cambiado por una figura que cazador de la cultura Selk'nam. Fuente: Crítica sur ( 7 noviembre sur ( 7 noviembre 2019 ) (https: /
criticasur.com ar/nota/21974/ en_punta_arenas_ derribaron un_busto_de menendez y en su lugar_colocaron el de un cazador se $\bar{l}$ k 039 nam)
Dagoberto Godoy. En el pedestal del monumento se lee la consigna "Nueva Constitución o Nada" y sobre la cabeza del toki flamea la bandera mapuche [Figura II]. Y otro tanto: en Punta Arenas, se ha vivido la destrucción de la estatua del estanciero español José Menéndez, identificado como símbolo del genocidio de la etnia Selk'nam, actualmente extinguida. Sobre el mismo plinto que sustentaba la figura de Menéndez, fue posteriormente colocada la figura de un cazador de esta cultura originaria de la Patagonia [Figura 12].

Frente a las críticas que grupos tradicionales han planteado por la vandalización de estos monumentos, han surgido otras voces que apelan a una lectura distinta. Una interpretación en esta línea, es la que señala que la destrucción es una reacción natural ante la imposición violenta que ha ejercido el Estado para que esos monumentos sean objetos de recordación. Refiriéndose a los monumentos vandalizados en la Araucanía, Ema de Ramón declaró: "iacaso no fue matonesco ir a plantar una figura de Pedro de Valdivia o Cornelio Saavedra a La Araucanía?" (De Ramón, 15 enero 2020). 
Figura 13

Muros del Centro Cultural Gabriela Mistral (ex UNCTAD). La ciudad y sus arquitecturas convertidas en

metáforas de

cambio y de nuevas

prácticas de

ciudadanía. Fuente:

Fotografía inédita

de Fernando Dowling Leal (2020). c] La ciudad: espacio de negociación de memorias, significados y valores

En un contexto de conflictos sociales, la ciudad misma, con todas sus componentes, es concebida como un patrimonio cuestionado, y al hacerlo en clave patrimonial, se convierte en un lugar de negociación de memorias sociales. Esta construcción de memorias constituye una verdadera geografía, donde se localizan, adquieren forma y apariencia concreta los monumentos en sus tres escalas: la ciudad, sus espacios públicos y su arquitectura. Los imaginarios de esa geografía marcan aspiraciones de grupos y personas que adquieren una configuración en el orden espacial de la ciudad (Claval, 20 I2, p. 32). En la ciudad histórica, la dinámica comunicacional del estallido expone una sociedad porosa y activa, donde el reclamo se expresa en un cuerpo urbano que se "tatúa" para exponer necesidades sociales invisibilizadas, y la arquitectura diluye su significado inicial (Manzi, 2020, p. I) [Figura I3]. En esta medida, es posible comprender cómo en la construcción social del patrimonio, la ciudad y sus redes funcionan como anclajes para la materialización de las representaciones sociales con sus respectivos signos (Castoriadis, 20 I3, p. 525).

Santiago, Valparaíso, La Serena, Concepción y Temuco se han convertido en escenarios urbanos de esas reapropiaciones sociales del patrimonio. La ciudad ha visto paralizar los rituales cotidianos que creíamos tan permanentes y sólidos (vivienda, servicios, comercio y

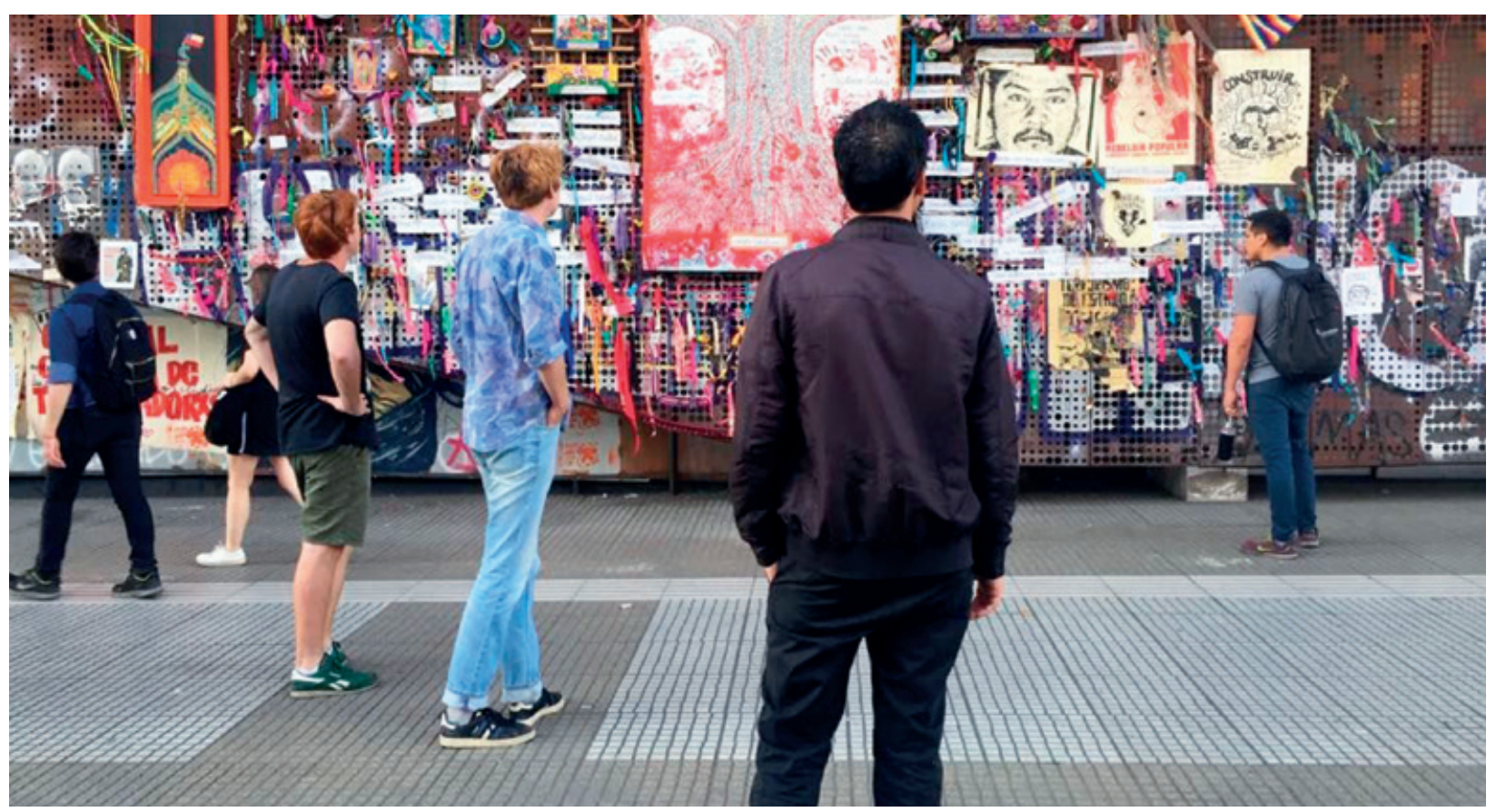


movilidad) para dar lugar a un control social y experiencia real de la biopolítica. La geografía urbana resultante se nos presenta con nuevos límites, cuadrantes policiaco-militares y espacios diferenciales, cuyos actores han cambiado sus roles y prácticas de uso. El costo ha sido la destrucción física y violencia sufrida por el patrimonio arquitectónico y urbano, canonizado por la legislación que intentaba protegerlo. En estas ciudades, los espacios de protesta urbana han actuado como territorios activados para diferentes proyectos colectivos que refieren a la Nación, al Estado, a las instituciones hegemónicas y a las comunidades más o menos marginadas, que sustentan modos diferenciados y contradictorios de transformación de la realidad y proyectarse en el tiempo. El conjunto de estas huellas más o menos visibles, entre lo vigente y lo caduco es lo que aparece como la esencia del conflicto patrimonial actual.

Desde esta perspectiva, podemos decir que la protesta social chilena se despliega en lo que Lefebvre ha denominado construcción del "espacio público democrático", metadiscurso que reivindica el derecho a existir y vivir en la ciudad, a través de la apropiación del espacio público (1975, p. 123-139). El concepto de ciudadanía, junto con expresar el acceso democrático a las decisiones políticas, alude también al sentido de pertenencia e identidad, de participación; hecho que permite que en la ciudad los habitantes sean reconocidos como sujetos activadores del espacio de la polis. La noción de espacio público y democrático que discute socialmente los símbolos del nuevo patrimonio, se está resolviendo a través de la apropiación del espacio público. La ciudad histórica vive una etapa que intenta recuperar su rol de civitas y de urbanitas a la vez, volviendo a activarse como ágora de debate colectivo.

El conjunto de símbolos urbanos implicados es rechazado, porque es percibido como dispositivo de represión de los grupos dominantes, pero, al mismo tiempo, canaliza la posibilidad de otros símbolos alternativos. Así, las prácticas sociales trasgreden los marcos físicos, reglamentarios y memoriales hegemónicamente autorizados, constituyendo actos legítimos de reapropiación del espacio público y de materialización del derecho a la ciudad (Oliva, 2020, p. 5). En las ciudades chilenas expuestas al estallido social, se observa la tendencia a la recomposición de un marco de referencias de orientación espacial y temporal [Figura 14]. Siguiendo a Iniesta (2009, p. 476), se trataría de un marco conformado por tres ejes complementarios. El primero se halla determinado por un deseo de encontrar un sentido a la experiencia existencial presente, mediante un conocimiento del pasado. En segundo término, está la construcción inconsciente de un relato histórico que facilita la activación política de la memoria y de las identidades privadas y colectivas. Y, en tercer lugar, fruto de los anteriores, aparece una reconstitución de los paisajes urbanos, en donde los grupos sociales activan sus conocimientos y narraciones, en los que, a su vez, comparecen los imaginarios logrados y los objetos patrimoniales que permiten el anclaje espacial de sus memorias. 



DISCUSIÓN

AS / Vol. 39. No59 / ENERO 2021 // ISSN impresa 07 I 6-2677 / ISSN digital 0719-6466 ESTALLIDO SOCIAL EN CHILE Y PROCESOS DE PATRIMONIALIZACIÓN: UN PARADIGMA DE RESIGNIFICACIÓN DE LAS MEMORIAS

Mario Ferrada Aguilar
De acuerdo al fenómeno observado en los casos expuestos, lo que merecería la mayor atención para entender el nuevo paradigma del patrimonio chileno es la identificación de las claves ocultas que esos discursos institucionales y sociales esconden en el contexto del conflicto. En primer lugar, están los acervos patrimoniales que dejan de ser relevantes y caen en obsolescencia, debido a que sus significados no sintonizan con las ideas o percepciones sociales contemporáneas. Luego, se encuentran los elementos arquitectónicos y/o urbanos que, previo al conflicto social no contaban con una valoración explícita, pero que a través de él son reactivados y patrimonializados para traducir la nueva realidad existencial de las comunidades. Por último, estarían aquellos monumentos que, reconocidos por el discurso oficial, institucional y legal, son interpretados por las tribus urbanas al interior del conflicto social como elementos violentadores y contrarios a los nuevos contenidos que se intentan instalar. Esta situación la vemos representada por la estatua de Manuel Baquedano en la Plaza Italia de Santiago o la del Monumento a los Héroes de lquique en Plaza Sotomayor de Valparaíso, a través de las que se rechaza el sentido elitista del poder, abogando por una mirada transversal, participativa y popular. De modo análogo, las acciones de amputación y recambio de símbolos en los monumentos de Francisco de Aguirre en La Serena, de Pedro de Valdivia en Temuco o de José Menéndez en Punta Arenas, reflejan la reacción ante la agresión perpetrada contra las voces de las etnias invisibilizadas en la historia del país. 
Figura 14

Durante el proceso de estallido social perspectivas urbanas de Santiago centro y del entorno a

la Plaza Victoria

de Valparaíso. La destrucción física y la entropía espacial esconden claves para la activación de proyectos colectivos. Fuentes: Fotografías inédita de Fernando Dowling Leal (2020) y de Mario Ferrada
En este sentido, podríamos identificar como elementos comunes a las situaciones expuestas en este trabajo, la articulación dinámica de las demandas sociales en torno a convertir el espacio público y los monumentos en dispositivos de trasgresión a los símbolos de la memoria institucionalizada. Es el caso de patrimonios reconvertidos en su significado, mediante discursos de identidades étnicas, sociales, de género, de clase e ideológicas, que transforman a los artefactos del patrimonio insertos en la ciudad en 'lugares políticos' del debate por la participación, la justicia y la dignidad, así como de los discursos marginados del relato oficial. De igual forma, los elementos particulares a cada caso estarían determinados por el grado de intensidad y persistencia del relato histórico que afecta a cada monumento y otorga nuevos usos, morfologías y significados al espacio público y la arquitectura que le rodea. Baste mencionar, en este sentido, la Plaza Italia o los entornos a los monumentos públicos de la tradición republicana, donde se extreman acciones de alteración física y marcajes a través de nuevos íconos, murales o acciones de arte para el espacio público, todo lo cual cambia momentánea o permanentemente el paisaje y las geografías urbanas cotidianas.

Es con esta claridad que adquiere sentido la técnica de la conservación, la gestión y la intervención en los elementos valorados patrimonialmente fruto del reclamo de las comunidades activas (Prats, 2005, p. 22). Una interpretación del efecto patrimonializador del estallido social chileno sería que nos enfrentamos a un escenario de definición y selección de lo que merece ser recordado y lo que no. Es por este motivo que constituiría un error de lectura y una artificiosa operación de marcha atrás reinstalar o relocalizar los monumentos derribados, o "higienizar" en su apariencia anterior los espacios cívicos reapropiados, como si nada de esto hubiese ocurrido.

Sin embargo, en el marco del nuevo paradigma que hemos tratado de delinear, también merece cuestionarse la arista material del patrimonio cultural que indudablemente ha sido afectado $y$, en algunos casos, altamente destruido. ¿Cuál es el límite aceptable para que del proceso de resignificación emerjan nuevos valores y nuevos tipos de patrimonios, sin que ello signifique la desaparición completa de los anclajes materiales de la memoria preexistente cuestionada? Porque, de lo que se trata, es de intentar dotar de mayor densidad de significados y valores a nuestro patrimonio, no de simplificarlo sobre la base de relevar sólo algunas memorias e historias, anulando otras. ¿Es posible administrar dicho propósito en un ambiente de convulsión social? Y, finalmente, ¿de qué manera los procesos de resignificación pueden ser algo más que una demanda social, para llegar a legitimarse e institucionalizarse mediante el consenso de las comunidades que lo promueven?

El impacto de las demandas por instalar nuevas memorias en la ciudad ha permitido que el patrimonio se active políticamente, a partir de grupos sociales cuyos intereses sociales, económicos y culturales pueden ser distintos, pero convergentes en la idea del derecho a ser 
Figura 15

El estallido

social, iniciado

en octubre de

2019 , con su

cúmulo de demandas

ha significado la

radical alteración

de los órdenes

cívicos normados

en la ciudad, junto

con la destrucción

de elementos

patrimoniales

por la tradición.

Fuente: Fotografía

inédita de Fernando

Dowling Leal

(2020). protagonistas de su desarrollo, y que su comprensión del patrimonio logre instalarse en la institucionalidad. En la Plaza Italia de Santiago, en los alrededores del Congreso Nacional y en las plazas de Valparaíso, o en los enclaves urbanos de La Serena, Concepción, Temuco y Punta Arenas, la crítica social, transformada en acción cultural, ha desnudado los enfoques de una noción simplificadora y verticalizada del patrimonio nacional. En los espacios públicos de algunas ciudades que hemos expuesto, en especial la Plaza Italia de Santiago, el conflicto social ha quebrado la idea de una única definición de ciudadanía, erosionando el discurso autorizado de los poderes e instituciones que la representan. La evidente destrucción física de los monumentos o la desintegración de los espacios públicos está siendo el alto precio que debemos pagar






\section{CONCLUSIONES}

para lograr la coexistencia de ciudadanías diversas, cargadas de imaginarios y valores, aún en proceso de configuración.

El estallido social ha roto el mito de la unidad nacional en torno a símbolos y patrimonios, mediante los cuales supuestamente estaríamos convocados a adherir a una sólida y única identidad estática. Por otro lado, la tensión que deviene del deseo por instalar la presencia urbana de otras memorias, fragmenta el discurso histórico aceptado y normado, por el cual los monumentos, los espacios urbanos, las arquitecturas y las estatuas protegidas son sacados de su naturalidad, para pasar a tener que enfrentarse a una coexistencia con las nuevas interpretaciones de la historia. Esto explicaría la iconoclastia y las nuevas imágenes heterópicas que emergen respecto del espacio histórico urbanizado, de los monumentos públicos "sacados de lugar" y de la arquitectura utilizada como reducto de apropiaciones espontáneas, mural de crítica y soporte de discursos inéditos [Figura 15].

Un elemento histórico central en la disputa por el patrimonio, que hoy se hace claramente perceptible, está determinado por la tendencia a utilizar el monumento como medio de destrucción política del relato patriarcal del poder, tendiente a desintegrar la correlación entre dominantes y dominados, abogando por nuevas formas de libertad, diversidad y justicia, que a la larga exigen formas de representación en elementos situados fuera del canon patrimonial autorizado. Como afirma Bengoa, detrás de todo, estaría el rechazo al imaginario de la sociedad feudal, actualmente liberal, que en el inconsciente colectivo de los sectores dominantes sigue representando el modelo de orden, norma y decencia (2006, p. 46). Un síntoma de este fenómeno, lo podemos percibir en la presencia de elementos comunes entre las demandas nacionales y las emanadas del pueblo mapuche. Ellos irían en la línea de la autodeterminación política o incremento de los niveles de democracia directa, recuperación territorial o reapropiación de los espacios ciudadanos, exigencia de derechos de lengua, o bien, respecto a formas de comunicación social nuevas y desmilitarización del Wallmapu (territorio mapuche) o rechazo del control político-militar en los espacios urbanos (Alvarado Lincopi, 2019, s/p).

Ante todo, debemos señalar que, debido a que este trabajo se desprende de la observación de un fenómeno aún en proceso de construcción, las conclusiones a las que podamos arribar muestran resultados provisorios y no definitivos. De igual forma, debemos considerar que las situaciones de resignificación del patrimonio chileno expuestas, si bien no son representativas del acontecer general del país, ni tampoco de cada ciudad en que ocurren, sí nos permiten deducir la existencia de una tendencia de comportamiento del patrimonio en otros casos análogos. Producto del quiebre social que vive el país, es posible reconocer una profunda crisis de representatividad del patrimonio cultural, de la que emergen procesos 
de resignificación y revalorización que ponen en juego la relación monumento-documento y mediante los cuales se vertebran nuevos discursos, historias y memorias.

Hemos intentado demostrar que, bajo las actuales condiciones de transformación social en Chile, se está gestando un innovador paradigma que afecta las bases epistémicas, axiológicas y metodológicas del patrimonio cultural. Las nuevas formas de apreciar, identificar y valorar el patrimonio se fundan en devolver a las comunidades su rol protagónico en la construcción social de sus historias y memorias. Es decir, un proceso de patrimonialización que reactiva nuestra relación con el espacio y el tiempo en la ciudad y sus monumentos. Que pone la atención en los procesos -y con ellos en los discursos y los imaginarios-, más que en los productos finales que definen los tipos de patrimonio a conservar. El estallido social chileno nos ha permitido tomar conciencia de la función principal del patrimonio al nivel de una entidad dinámica y cambiante: la de aspirar a ser un "bien común". Cuando éste es escindido de su contenido social y de sus administradores legítimos, inicia una agonía, que se recupera solamente cuando resurge el sentido de ciudadanía. El patrimonio es, junto con su capacidad de rememoración, un asunto de control y poder, que siempre instalará una forma de apreciar el presente, desplazando las hegemonías y los flujos representativos de un lugar a otro.

El fenómeno expuesto ha abierto la necesidad de elaborar una renovada historiografía de los nuevos relatos que hablan del ethos de los patrimonios nacientes, de sus formas diversas de aparecer, de sus contenidos de valor y de sus inéditos actores sociales. Un desafío así nos obliga a aceptar el conflicto social como parte sustancial de cualquier proceso real de patrimonialización y a salir del cómodo y resignado espacio de las certezas disciplinares y profesionales que respecto del patrimonio creíamos tan seguras, claras y estables. En un momento de transformación socio-patrimonial, es innegable la enorme responsabilidad que adquiere el Estado para garantizar el adecuado flujo representativo de discursos portadores de identidades, historias, memorias individuales y sociales. Se trataría de posibilitar que en estos espacios ciudadanos la negociación de historias y memorias se desempeñe libre y democráticamente, en un estado de diálogo en la parrhesia que le es propia a un ágora. La ciudad, sus espacios públicos, sus arquitecturas y elementos monumentales, son los lugares para expresar y evaluar cómo pueden convivir los nuevos patrimonios con los preexistentes. 


\section{REFERENCIAS BIBLIOGRÁFICAS}

ALVARADO LINCOPI, C. (8 noviembre 2019). Derribar símbolos coloniales: Un nuevo acto político que se suma en las protestas en Chile. Interferencia. Recuperado de https://interferencia.cl/articulos/derribar-simbolos-coloniales-un-nuevo-acto-politico-que-se-suma-en-las-protestas-en-chile

ARANDA. F. (2020). En Ojeda Pereira, I. (Ed.). Postales del estallido social chileno. Sentires colectivos. Entre la vivencia y la memoria. Valdivia: Némesis.

BENGOA, JOSÉ (2006). La comunidad reclamada. Identidades, utopías y memorias en la sociedad chilena. Santiago de Chile: Editorial Catalonia.

CASTORIADIS, C. (2013). La institución imaginaria de la sociedad. Buenos Aires: Tusquets Editores.

CLAVAL, P. (2012). Mitos e imaginarios en geografía. En: Lindón, A. y Hiernaux, D. (Dir.). Geografías de lo imaginario (pp. 29-48). México D.F.: Anthropos, Universidad Autónoma Metropolitana.

CNN Chile (23 febrero 2020). Atacan monumento Héroes de lquique en Valparaíso con piedras y pintura: La Armada condenó el acto. CNN Chile. Recuperado de https://www.cnnchile.com/pais/atacan-monumento-valparaiso-armada-condena_20200223

DAVALLON, J. (2010). The Game of Heritagization. En: Roigé, X. y Frigolé, J (Eds.). Constructing Cultural and Natural Heritage. Parks, Museums and Rural Heritage (pp. 39-62). Girona: ICRPC.

DE RAMÓN, E. (15 enero 2020). Patrimonio y estallido: No hay que asustarse. Hay que asustarse cuando no pasa nada. Radio ADN. Recuperado de https://www. adnradio.cl/tiempo-libre/2020/01/15/emma-de-ramon-patrimonio-y-estallidono-hay-que-asustarse-hay-que-asustarse-cuando-no-pasa-nada-4002942.html

DE SOUZA, M. V. (2020). Concepción: El trabajador del comercio informal de calle. La producción efímera del espacio en la crisis social. Revista Arquitecturas del Sur, 38(57), pp. 146-161.

El Mostrador Cultura (11 marzo 2020). Mundo cultural dividido: organizaciones sociales llaman a no aprobar Ley del Patrimonio hecha "entre cuatro paredes". El Mostrador. Recuperado de https://www.elmostrador.cl/dia/2020/03/11/mundo-cultural-dividido-organizaciones-sociales-llaman-a-no-aprobar-ley-del-patrimonio-hecha-entre-cuatro-paredes

GAETE, C. (30 junio 2020). En: Jacinta, M., Protestas contra monumentos colonialistas: El otro estallido chileno que la pandemia dejó en pausa. CNN. Recuperado de https://www.cnnchile.com/pais/protestas-monumentos-colonialistas-otro-estallido-social_20200630

GARCÍA CANCLINI, N. (1999). Los usos sociales del patrimonio cultural. En: Aguilar Criado, E. (Ed.), Cuadernos Patrimonio Etnológico. Nuevas perspectivas de estudio (pp. 16-33). Consejería de Cultura, Junta de Andalucía.

INIESTA, M. (2009). Patrimonio, ágora, ciudadanía. Lugares para negociar memorias productivas. En: Vinyes, R. (Ed.), El Estado y la memoria. Gobiernos y ciudadanos frente a los traumas de la historia (pp. 467-498). Barcelona: RBA Libros. LARRAín, J. (2010). El concepto de ideología Postestructuralismo, Postmodernismo y Postmarxismo. (Volumen 4). Santiago de Chile: LOM Ediciones.

LEFEBVRE, H. (2006). La presencia y la ausencia. Contribución a la teoría de las representaciones. México D. F.: Fondo de Cultura Económica.

LEFEBVRE, H. (1975). El derecho a la ciudad. Barcelona: Península.

LORENZO CADARZO, P. L. (2001). Principales teorías sobre el conflicto social. NORBA, Revista de Historia, (15), pp. 237-254.

MANZI ZAMUDIO, G. (2020). La ciudad de Santiago resignificada como corporeidad comunicacional temporal en tiempos de estallido social. Revista Arquitecturas del Sur, 38 (57), pp. 162-181.

OLIVA SAAVEDRA, C. (2020). Monumentos en el estallido social como expresión material del derecho a la ciudad. Revista Planeo, enero, (42), pp. 1-6.

PRATS, LI. (2005). Concepto y gestión del patrimonio local. Cuadernos de Antropología Social de la Universidad de Buenos Aires, (21), pp. 17-35.

RIEGL, A. (1987). El culto moderno a los monumentos. Madrid: Visor.

ROIGÉ, X. Y FRIGOLÉ, J. (2010). Introduction. En Roigé, X. y Frigolé, J (Eds.). Constructing Cultural and Natural Heritage. Parks, Museums and Rural Heritage (pp. 9-24). Girona: ICRPC.

SÁNCHEZ CARRETERO, C. (2017). Hacia una antropología del conflicto aplicada al patrimonio. En Santa María Campos, B. (Coord.). Geopolíticas patrimoniales: de culturas, naturalezas e inmaterialidades. Una mirada etnográfica (pp. 215230). Madrid: Neopatria.

SIMMEL, G. (2014). Sociología: estudios sobre las formas de socialización. México D.F.: Fondo de Cultura Económica. 